\title{
Manejo pesqueiro na calha do Rio Iça (AM) como ferramenta de sustentabilidade íctica e social
}

O manejo pesqueiro desenvolvido na Reserva de Desenvolvimento Sustentável de Mamirauá foi adotado em Santo Antônio do lça como inciativa da Secretaria Executiva de Pesca e Aquicultura da Secretaria de Estado de Produção Rural do estado do Amazonas, para estimular a vocação produtiva do município na explotação de recursos pesqueiros e aproveitar sua posição estratégica na região de tríplice fronteira entre Peru, Colômbia e Brasil, onde o comércio de pescado é marcante. Os dados do monitoramento da pesca e comercialização foram coletados nos anos de 2012, 2013 e 2014. Nas análises, foram empregadas técnicas de estatística descritiva, proposição de modelos para descrever a relação peso-comprimento do pirarucu (Arapaima gigas) e tambaqui (Colossoma macropomum), regressão linear simples para descrever o aumento no quantitativo de pirarucu a cada ano, a determinação do faturamento a partir (Arapaima gigas) e tambaqui (Colossoma macropomum), regressão linear simples para descrever o aumento no quantitativo de pirarucu a cada ano, a determinação do faturamento a partir georreferenciadas 25 comunidades e 142 lagos com potencial para o manejo; porém, só foram utilizados nove em decorrência de fatores ambientais e logísticos que limitaram as capturas. O aumento no quantitativo e na densidade do pirarucu foi observado em todos os ambientes monitorados, assim como do comprimento médio total e peso médio total dos indivíduos capturados. 0 estudo dos estádios gonadais do pirarucu permitiu observar que os indivíduos maiores e mais pesados tendem a estar nas três últimas fases dos estádios gonadais durante o período de despesca. As capturas de pirarucu totalizaram $50.336 \mathrm{~kg}$ em 2012, 34.657kg em 2013 e $46.800 \mathrm{~kg}$ em 2014; e de tambaqui, $1.882 \mathrm{~kg}$ em 2013 e $2.542 \mathrm{~kg}$ em 2014 . No ano de 2014 foram produzidos $390 \mathrm{~kg}$ de aruanã (Osteoglossum bicirrhosum), 119kg de surubim (Pseudoplatystoma spp.) 4.008kg de pirapitinga (Piaractus brachypomus) e $9.450 \mathrm{~kg}$ de jaraqui (Semaprochilodus spp.). A comercialização da produção nos três anos de manejo resultou em um faturamento total estimado em $R \$ \$ 607.667,50$, beneficiando 85 pescadores e 763 familiares. Esses resultados demonstram a eficiência do manejo na conservação do recurso pesqueiro.

Palavras-chave: Pesca sustentável; Pirarucu e tambaqui; Alto-Solimões.

\section{Fishing management in the Iça River (AM) channel as a tool for social and ethical sustainability}

\begin{abstract}
The fishery management developed at the Mamirauá Sustainable Development Reserve was adopted in Santo Antônio do Iça as an initiative of the Executive Secretariat of Fisheries and Aquaculture of the State Selo of its strategic position in the triple border region between Peru, Colombia and Brazil, where the fish trade is remarkable. Data from fisheries monitoring and marketing were collected in of its strategic position in the triple border region between Peru, Colombia and Brazil, where the fish trade is remarkable. Data from fisheries monitoring and marketing were collected in
2012,2013 and 2014. In the analyzes, descriptive statistics techniques, model propositions to describe the weight-length relationship of pirarucu (Arapaima gigas) and tambaqui (Colossoma macropomum) were used. ), simple linear regression to describe the increase in the quantity of pirarucu each year, the determination of the revenue from the product between quantity ( $\mathrm{kg}$ ) and marketing price (R\$) for each species and the income generated from the division of revenues among fishermen involved in management. 25 communities and 142 lakes with potentia for management were georeferenced; However, only nine were used due to environmental and logistical factors that limited catches. The increase in quantity and density of pirarucu was observed in all monitored environments, as well as in the total average length and total average weight of the captured individuals. The study of the gonadal stages of pirarucu showed that the largest and heaviest individuals tend to be in the last three phases of the gonadal stages during the harvesting period. Catches of pirarucu totaled 50,336kg in 2012,34,657kg in 2013 and $46,800 \mathrm{~kg}$ in 2014; and tam $4,008 \mathrm{k}$ in 2014; and (hi) .). The comm estimated total revenue of $\mathrm{R} \$ 607.667,50$, benefiting 85 fishermen and 763 family members. These results demonstrate the efficiency of management in the conservation of fishery resources.

Keywords: Sustainable fishing; Pirarucu and tambaqui; High-Solimões.
\end{abstract}

Topic: Desenvolvimento, Sustentabilidade e Meio Ambiente

Reviewed anonymously in the process of blind peer.
Received: 19/08/2018

Approved: 26/08/2018

Charles Hanry Faria Junior (iD)

Universidade Federal do Oeste do Pará, Brasil

http://orcid.org/0000-0002-2124-1351

charlesufopa@gmail.com

Hilberneau Holanda Bessa Neto (iD

Universidade Federal do Amazonas, Brasil http://lattes.cnpq.br/1266637467163132

http://orcid.org/0000-0002-1424-7413

hilberneau@yahoo.com.br

Thiago Marinho Pereira (iD

Universidade Federal do Oeste do Pará, Brasil

http://lattes.cnpq.br/5204637707676338

http://orcid.org/0000-0002-4340-0130

tmarinhopereira@gmail.com

d

DOI: 10.6008/CBPC2179-6858.2018.006.0022
Referencing this:

FARIA JUNIOR, C. H.; BESSA NETO, H. H.; PEREIRA, T. M.. Manejo pesqueiro na calha do Rio Iça (AM) como ferramenta de sustentabilidade íctica e social. Revista Ibero-Americana de Ciências Ambientais, v.9, n.6, p.213-229, 2018. DOI: http://doi.org/10.6008/CBPC2179-6858.2018.006.0022 


\section{INTRODUÇÃO}

A pesca em águas interiores é uma atividade antiga e de importância social, cultural e econômica para a região amazônica, historicamente praticada por distintas categorias de pescadores, mediante a utilização de embarcações com diferentes características físicas (multifrota) e o uso de diversificados aparelhos de capturadas (multipetrechos), o que resulta uma produção diversificada (multiespecífica), formas diferenciadas de captura, organização para a produção e comercialização (PETRERE, 1978a, 1978b, 1982, 1992; IPT, 1979; BARTHEM et al., 1992; CERDEIRA et al., 1997; BATISTA et al., 1998; RUFFINO, 2000; ALMEIDA et al., 2001; CARDOSO et al., 2004; FARIA-JUNIOR; BATISTA, 2006; IBAMA, 2007; BRASIL, 2012; FARIA-JUNIOR, 2013; COELHO et al., 2017; CARDOSO et al., 2017; BRELAZ et al., 2018).

Essa atividade recebeu um grande estímulo com a edição do Decreto-Lei 221/67, que viabilizou o aumento da produção pesqueira a partir de financiamentos para a aquisição de embarcações de pesca, aparelhos de captura, construção e modernização de indústrias de beneficiamento do pescado e empresas ligadas ao setor pesqueiro, que receberam isenção de impostos (PARENTE, 1996).

Além desse estímulo, o crescimento populacional dos centros urbanos na Amazônia, o aumento da demanda de pescado, a maior inserção de mão-de-obra envolvida na pesca e atividades vinculadas, a estruturação de grandes mercados consumidores e a ótica econômica envolvida na cadeia produtiva, resultaram na intensificaram da pesca e o direcionamento da pressão de captura sobre espécies de maior valor comercial e preferência popular, levaram alguns estoques de peixes a apresentarem indícios de sobrepesa (MCGRATH et al., 1993; CRAMPTON, 1999; FARIA-JUNIOR, 2013).

O pirarucu (Arapaima gigas) e o tambaqui (Colossoma macropomum) são espécies que apresentaram sinais de sobre-exploração pesqueira, como a redução no volume de desembarque, menor comprimento médio dos indivíduos pescados e o aumento do valor de comercialização (HILBORN et al., 1992; ISAAC et al., 1993; QUEIROZ et al., 1999; CASTELLO et al., 2010), o que demandou a adoção de medidas de restrição de captura, na ótica da conservação dessas espécies, como a Instrução Normativa no 34, de 18 de junho de 2004 e Instrução Normativa no 35 de 29 se setembro de 2005. De forma complementar, o Estado do Amazonas editou a Instrução Normativa no 31, de 1ㅇ de junho de 2005, proibindo assim, a captura, a comercialização e o transporte do pirarucu no Estado do Amazonas ao longo de todo o ano, excluindo dessa proibição, os exemplares oriundos do cultivo devidamente legalizados, bem como os exemplares provenientes de áreas manejadas.

O manejo de pirarucus em ambientes de várzea na Amazônia segue o modelo de manejo participativo desenvolvido na Reserva Mamirauá, estado do Amazonas, em 1999. Tem como princípio a participação dos pescadores ribeirinhos das comunidades usuárias dos lagos a serem manejados, que recebem apoio de técnicos, extensionistas e pesquisadores de organizações governamentais e não governamentais. Esse modelo participativo tem gerado expressivos resultados nos âmbitos social, ecológico e econômico e vem se disseminando rapidamente entre os municípios do Estado do Amazonas, Estados vizinhos e Países fronteiriços da região Amazônica (CASTELLO et al., 2013). 
Nesse cenário, Santo Antônio do Iça, é o quarto maior município da mesorregião do Alto Solimões, onde a base econômica é voltada para a agricultura, a pecuária e a pesca. Por sua vocação para a pesca, no ano de 2009, a Secretaria de Estado de Produção Rural do Amazonas deu início as ações de manejo do pirarucu na região, aos moldes de Mamirauá, Maraã, Fonte Boa e Jutaí, obtendo a primeira cota de despesca autorizada pelo Instituto Brasileiro do Meio Ambiente e dos Recursos Naturais Renováveis - IBAMA em 2012. Nesse contexto, o presente trabalho apresenta uma análise dos resultados ambientais, econômicos e sociais do manejo pesqueiro na calha do Rio Iça nos anos de 20121, 2013 e 2014, para contribuir com informações que subsidiem o gerenciamento da atividade pesqueira regional.

\section{METODOLOGIA}

O município de Santo Antônio do Iça se localiza na região do Alto Solimões (S $03^{\circ} 06^{\prime 2} 28^{\prime \prime}$; W $\left.67^{\circ} 56^{\prime} 48^{\prime \prime}\right)$, e as áreas de manejo estudadas se distribuem ao longo da calha do Rio Içá, em ambientes de lagos. A base de dados primários analisada foi coletada por técnicos vinculados à Secretaria Executiva de Pesca e Aquicultura da Secretaria de Estado de Produção Rural do Amazonas - SEPA/SEPROR nos anos de 2012, 2013 e 2014.

Entre as informações coletadas constam: ambientes mapeados - localização geográfica, denominação e área do lagos; comunidade - localização geográfica, nome, quantidade de pescadores e número de dependentes; para o pirarucu (Arapaima gigas) - contagem (quantidade) de juvenis e adultos existentes nos lagos, quantidade despescada e comercializada, comprimento total $(\mathrm{m})$, peso total $(\mathrm{kg})$, identificação do sexo e estádio de maturação gonadal obtido macroscopicamente segundo o método proposto por Vazzoler (1996) e valor de comercialização por quilograma (R\$); para o tambaqui (Colossoma macropomum) - quantidade despescada e comercializada, comprimento total ( $\mathrm{cm})$, peso total $(\mathrm{kg})$ e valor de comercialização por quilograma ( $\mathrm{R} \$$ ); demais espécies de peixes - peso $(\mathrm{kg})$ e valor de venda $(\mathrm{R} \$$ ) por espécie. Dados secundários foram obtidos de estudos realizados nas demais áreas de manejo do Amazonas e Pará.

As informações foram analisadas com o emprego de ferramentas da estatística descritiva (medidas de tendência central) e propostos modelos matemáticos para representar a tendência de aumento no quantitativo de pirarucus a cada ano, a influência da variável independente comprimento total $(\mathrm{m})$ sobre a variável dependente peso total (kg) dos exemplares de pirarucu e tambaqui despescados (ZAR, 1999).

Os benefícios sociais e econômicos do manejo foram estimados com base no faturamento com a comercialização da produção anual, a partir do somatório do produto entre o quantitativo de peixes explotados e comercializados em cada comunidade por seu respectivo valor de comercialização, e a renda gerada, determinada com base no quantitativo de pescadores envolvidos em cada comunidade.

\section{RESULTADOS}

\section{Histórico do manejo do município de Santo Antônio do Içá}

Por se localizar nas proximidades da região de tríplice fronteira entre Brasil, Peru e Colômbia, o município de Santo Antônio do Içá possui vantagens para a comercialização de pescado na região do Alto 
Solimões, fato que motivou os gestores da Secretaria Executiva de Pesca e Aquicultura - SEPA, vinculada à Secretaria do Estado da Produção Rural do Estado do Amazonas - SEPROR, a contratar em 2009 um Engenheiro de Pesca para gerenciar a Unidade de Beneficiamento de Pescado do Polo do Pescado II - UBPP II/SEPA/SEPROR, localizada no município.

O profissional realizou um estudo do panorama da utilização dos recursos pesqueiros que resultou em um documento apresentado a SEPA/SEPROR, representantes de pescadores e do poder público local, expondo a falta de controle do desembarque e comercialização do pescado no município, indícios da atuação de sulambeiros ${ }^{1}$ oriundos dos países fronteiriços (Colômbia e Peru), que invadiam as áreas de pesca das comunidades locais, com reflexo nos estoques de aruanã (Osteoglossum bicirrhosum) e outras espécies, já evidenciados nos relatos (de moradores, pescadores e vendedores de pescado) da diminuição da oferta e tamanho médio dos exemplares comercializados, além do comércio clandestino, com o total desrespeito ao período de reprodução ou da legislação que proibi a captura e a comercialização do pirarucu e do tambaqui.

No final de 2009, representantes da Associação de Moradores da Área do Projeto de Assentamento Florestal - PAF/Rio Iça, legalizada no Instituto Nacional de Colonização e Reforma Agrária - INCRA, se reuniram com a gerência da UBPP II para buscar soluções direcionadas ao uso dos recursos pesqueiros na área do PAF. Essa reunião estimulou em 2010 uma ação inicial conjunta para realizar excursões e reuniões nas comunidades que integram o PAF/Rio Içá com o objetivo de mapear as áreas de pesca e conscientizar os pescadores e comunitários para o apoio ao trabalho de conservação dos lagos com potencial para o manejo pesqueiro. Entretanto, como a área do PAF/Rio Içá constituía apenas uma pequena parte do potencial do município de Santo Antônio do Içá, foi cogitada a possibilidade de realizar um levantamento mais amplo dessa potencialidade.

Uma execução foi planejada, contando com uma equipe composta por representantes dos pescadores, comunitários, Governo Municipal e Governo do Estado, coordenada pela gerência da UBPP II, para realizar uma viagem de 20 dias ao longo da Calha do Rio Içá, desde a comunidade de Ipiranga (área militar), localizada na fronteira com a Colômbia, até a sua desembocadura com o rio Solimões, com a finalidade de realizar o levantamento de dados (informações dos pescadores e da pesca, características dos ambientes de pesca e principais espécies exploradas), georreferenciamento de comunidades, lagos e demais áreas de pesca do município, reuniões e palestras com a temática dos 'acordos de pesca' e da necessidade de vigilância das áreas de pesca de cada comunidade.

A excursão resultou no georreferenciamento de 25 comunidades e 142 lagos ao longo da calha do Rio Içá, bem como da confirmação dos aspectos negativos da falta de controle da pesca mediante o relato de pescadores e familiares, das dificuldades (para subsistência e ganho econômico) que enfrentavam devido a disputa pelo recurso e relatos de ameaças, a redução da quantidade e porte de algumas espécies de peixes nos ambientes de pesca como resultado da depredação realizada por parte de pescadores externos que invadiam os lagos próximos as comunidades. No aspecto positivo, a excursão permitiu identificar o potencial

\footnotetext{
${ }^{1}$ Sulambeiros: denominação dada aos pescadores que capturam aruanã quando estão exercendo o cuidado parental com sua prole, para capturar e vender os alevinos para o mercado exterior, como peixe ornamental.
} 
dos lagos para o manejo do pirarucu, com alguns ambientes apresentando grandes quantidades de pirarucu, tambaqui e outras espécies.

Essas informações subsidiaram a realização de reuniões intercomunitárias e assembleias gerais na sede do município de Santo Antônio do Iça, contando com a participação de representantes de comunidades inseridas na proposta de 'Plano de Manejo Pesqueiro do Rio Iça' e de representantes de outras comunidades com sistemas de lagos mapeados e que já realizavam ações de proteção dos seus ambientes de pesca com vistas. Como etapa complementar do processo de implantação do manejo pesqueiro direcionado ao pirarucu, foi realizado em julho de 2011 um curso para certificação de contadores de pirarucu e em agosto, a primeira contagem em 06 lagos, de 06 comunidades, que apresentavam maior potencial pesqueiro, seguindo a metodologia do manejo iniciado na Reserva de Desenvolvimento Sustentável de Mamirauá - RDS Mamirauá.

Os dados da contagem foram utilizados para a elaboração de um relatório, encaminhado ao Instituto Brasileiro do Meio Ambiente e dos Recursos Naturais Renováveis - IBAMA para a solicitação da primeira cota de captura, liberada para o ano de 2012. Outras expedições foram realizadas contanto com a participação da Associação das Comunidades Manejadoras do Rio Iça - ASSCOMAL para ampliar e realizar ajustes no processo de mapeamento da área, resultando na seleção de 19 lagos de 11 comunidades para a realização do manejo nos anos de 2013 e 2014. Esses mesmos ambientes passaram a ser utilizados para a pesca do tambaqui (Colossoma macropomum) e outras espécies.

\section{Dados qualitativos e quantitativos do processo de contagem e despesca do pirarucu e do tambaqui.}

A primeira contagem do pirarucu, realizada no ano de 2012, totalizou 10.819 peixes, entre bodecos ${ }^{2}$ e adultos ${ }^{3}$, resultou uma cota de captura liberada pelo IBAMA de 1.082 indivíduos adultos $(23,71 \%)$ e uma despesca de 1.036 peixes (95,75\%). Em 2013, foram contados 33.246 pirarucus (14.335 adultos), o que resultou em uma cota de 3.740 pirarucus $(26,09 \%)$, porém, só foram despescados 978 peixes $(26,14 \%)$. Em 2014 foram contados 51.005 pirarucus (22.036 adultos), resultando uma cota de 5.039 (22,87\%), mas despescados somente 960 peixes (19,05\%) (quadro 1).

Quadro 1: Resultado da contagem realizada por comunidade e lagos em cada ano

\begin{tabular}{|c|c|c|c|c|c|c|c|c|}
\hline \multirow{2}{*}{ COMUNIDADES } & \multirow{2}{*}{ Lago } & \multirow{2}{*}{ Área (ha) } & \multicolumn{2}{|c|}{2012} & \multicolumn{2}{|c|}{2013} & \multicolumn{2}{|c|}{2014} \\
\hline & & & Bodeco & Adulto & Bodeco & Adulto & Bodeco & Adulto \\
\hline São Lázaro & Paracuubá & 44,903 & & & 362 & 247 & 514 & 358 \\
\hline \multirow{2}{*}{ São Sebastião } & Branco & 18,5542 & 149 & 47 & 230 & 186 & 338 & 315 \\
\hline & Japiim & 30,0528 & & & 204 & 157 & 322 & 272 \\
\hline Santa Vitória & Piranha & 72,4672 & 25 & 5 & 164 & 134 & 288 & 239 \\
\hline Nova Jesuana & Canoa Velha & 42,8436 & & & 356 & 261 & 587 & 410 \\
\hline \multirow{3}{*}{ Boa União } & Tucunaré & 10,5144 & & & 332 & 211 & 364 & 335 \\
\hline & Quilha & 7,8699 & & & 120 & 53 & 227 & 130 \\
\hline & Cumprido & 7,4343 & & & 298 & 156 & 483 & 261 \\
\hline \multirow{3}{*}{ São Pedro } & Apapari & 584,1055 & 4.402 & 3.861 & 8.123 & 6.899 & 11.941 & 9.728 \\
\hline & Branco do Apapari & 11,3914 & & & 176 & 140 & & \\
\hline & Timbó & 6,2204 & & & 478 & 181 & & \\
\hline São João do Lago Grande & Grande do Artur Leão & 877,5535 & 131 & 455 & 937 & 761 & 1.508 & 1.209 \\
\hline
\end{tabular}

${ }^{2}$ Bodecos: juvenis de pirarucu com comprimento total abaixo de $1,50 \mathrm{~m}$.

${ }^{3}$ Adultos: exemplares de pirarucu com tamanho comprimento total $\geq 150 \mathrm{~cm}$. 


\begin{tabular}{|c|c|c|c|c|c|c|c|c|}
\hline \multirow{3}{*}{ Ipiranga } & Comprido do Ipiranga & 33,0355 & & & 453 & 259 & 684 & 383 \\
\hline & Centro do Ipiranga & 238,616 & & & 2.253 & 1.560 & 3.402 & 2.371 \\
\hline & Gloria & 433,7953 & & & 1.296 & 980 & 1.957 & 1.509 \\
\hline Moinho I & Tapagem & 14,6488 & & & 1.302 & 544 & 1.889 & 799 \\
\hline \multirow{4}{*}{ Moinho II } & Comprido da Tapagem & 6,8353 & & & 435 & 485 & 644 & 737 \\
\hline & Encrenca & 21,6225 & 948 & 146 & 1.158 & 939 & 1.644 & 1.361 \\
\hline & Cachimbo & 19,6469 & & & 234 & 182 & 402 & 336 \\
\hline & Augusto & 11,9234 & 600 & 50 & & & & \\
\hline \multirow{2}{*}{ Jurupari } & Porquinho & & & & & & 1.121 & 953 \\
\hline & Pião & & & & & & 654 & 330 \\
\hline \multicolumn{2}{|l|}{ Total por porte } & & 6.255 & 4.564 & 18.911 & 14.335 & 28.969 & 22.036 \\
\hline \multicolumn{2}{|l|}{ Total Geral } & & \multicolumn{2}{|c|}{10.819} & \multicolumn{2}{|c|}{33.246} & \multicolumn{2}{|c|}{51.005} \\
\hline
\end{tabular}

A cada ano subsequente, as contagens apresentaram um aumento no quantitativo percentual de pirarucus para todos os lagos, com amplitude percentual variando de 9,64\% (Tucunaré) a 615,27\% (Grande do Artur Leão) para os bodecos e de $41,01 \%$ (Apapari) a 2.580,00\% (Piranha) para os adultos. Em termos de crescimento no número de peixes por ambiente, foi determinada uma amplitude de bodecos de 0,15 peixes/ha (Grande do Artur Leão) a 128,95 peixes/ha (Tapagem) e de 0,07 peixes/ha (Piranha) a 107,86 peixes adultos/ha (Comprido da Tapagem), onde a densidade geral (total de pirarucus dividido pela soma da área dos lagos) foi de 4,34 peixes/ha em 2012, de 13,33 peixes/ha em 2013 e de 20,45 peixes/ha em 2014. Para os lagos utilizados nos três anos, o aumento do quantitativo de pirarucus a cada ano apresentam coeficientes de regressão robustos, conforme se pode ver no quadro 2 .

Quadro 2: Crescimento linear do quantitativo de pirarucus manejados nos anos de 2012, 2013 e 2014.
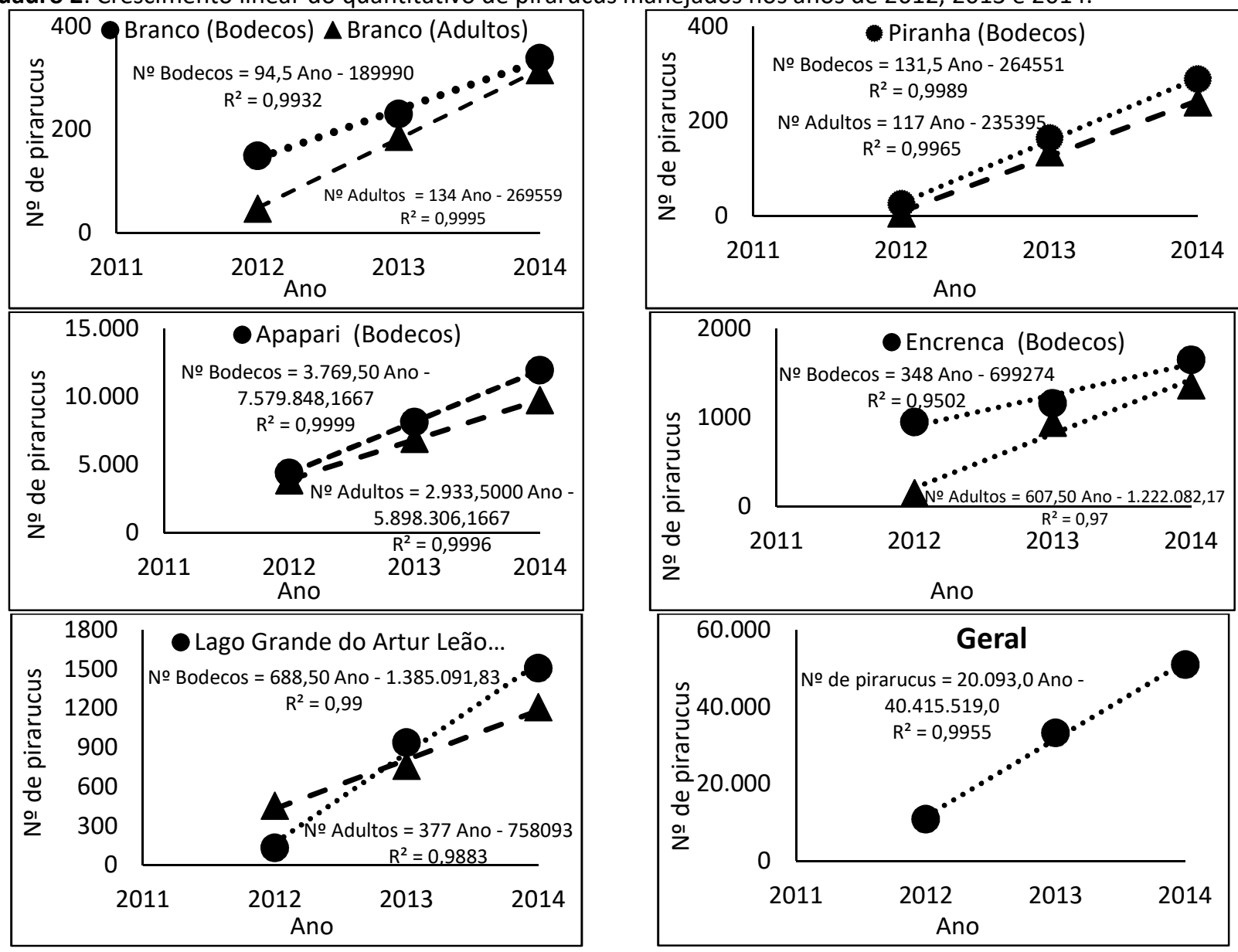
Uma análise comparativa do comprimento médio independente do gênero dos pirarucus adultos mostrou aumento de 2012 para 2013 e uma redução de 2013 para 2014, porém, é possível observar que as fêmeas tendem a ser maiores que os machos. A média de peso por individuo segue a mesma tendência, onde as fêmeas possuem peso médio maior que os machos, proposta no quadro 3 .

Quadro 3: Média de comprimento e peso total dos pirarucus despescados nos anos de 2012, 2013 e 2014.

\begin{tabular}{|c|c|c|c|c|c|c|c|}
\hline \multirow{2}{*}{ Ano } & \multirow{2}{*}{ Porte } & \multicolumn{3}{|c|}{ Comprimento total médio ( \pm Desvio Padrão) $(\mathrm{m})$} & \multicolumn{3}{|c|}{ Peso total médio ( \pm Desvio Padrão) $(\mathrm{kg})$} \\
\hline & & Geral & Fêmeas & Machos & Geral & Fêmeas & Machos \\
\hline \multirow{2}{*}{2012} & Adulto & $1,71( \pm 0,17)$ & $1,72( \pm 0,18)$ & $1,69( \pm 0,16)$ & $46,70( \pm 16,20)$ & $48,98( \pm 18,07)$ & $44,72( \pm 14,09)$ \\
\hline & Bodeco & $1,42( \pm 0,05)$ & $1,42( \pm 0,05)$ & $1,42( \pm 0,0$ & $29,30( \pm 6,16)$ & $29,32( \pm 4,10)$ & $29,28( \pm 7,79)$ \\
\hline \multirow{2}{*}{2013} & Adulto & $1,77( \pm 0,18)$ & $1,80( \pm 0,18)$ & $1,75( \pm 0,17)$ & $49,75( \pm 17,71)$ & $52,60( \pm 17,93)$ & $47,46( \pm 17,23)$ \\
\hline & Bodeco & $1,41( \pm 0,08)$ & $1,43( \pm 0,07)$ & $1,40( \pm 0,08)$ & $24,25( \pm 7,87)$ & $24,70( \pm 13,03)$ & $24,48( \pm 6,54)$ \\
\hline \multirow{2}{*}{2014} & Adulto & $1,74( \pm 0,19)$ & $1,76( \pm 0,45)$ & $1,72( \pm 0,37)$ & $46,78( \pm 17,42)$ & $46,96( \pm 17,31)$ & $46,66( \pm 17,55)$ \\
\hline & Bodeco & $1,42( \pm 0,15)$ & $1,42( \pm 0,85)$ & $1,41( \pm 0,23)$ & $25,15( \pm 13,77)$ & $25,72( \pm 12,23)$ & $24,78( \pm 16,45)$ \\
\hline
\end{tabular}

Uma análise entre intervalos de classe de comprimento total independente do gênero permitiu mostrar que o número de bodecos abatidos diminuiu a cada ano, e apesar de ocorrerem oscilações, observase uma tendência de captura de indivíduos adultos com maior comprimento, quando comparados ao primeiro ano de manejo. Em termos de biomassa $(\mathrm{kg})$, no ano de 2012 as capturas resultaram em $50.336 \mathrm{~kg}$ (48.197kg de adultos e $2.139 \mathrm{~kg}$ de bodecos), em 2013 foram $34.657 \mathrm{~kg}$ (33.323kg de adultos e $1.334 \mathrm{~kg}$ de bodecos) e em 2014 foram $46.800 \mathrm{~kg}$ (45.628kg de adultos e $1.172 \mathrm{~kg}$ de bodecos), sendo que apesar da redução em 2013, ocorreu um aumento de indivíduos para os intervalos de peso de $0 \vdash 30 \mathrm{~kg}$ e de $30 \vdash 60 \mathrm{~kg}$ em relação ao ano de 2012 (figura 1).
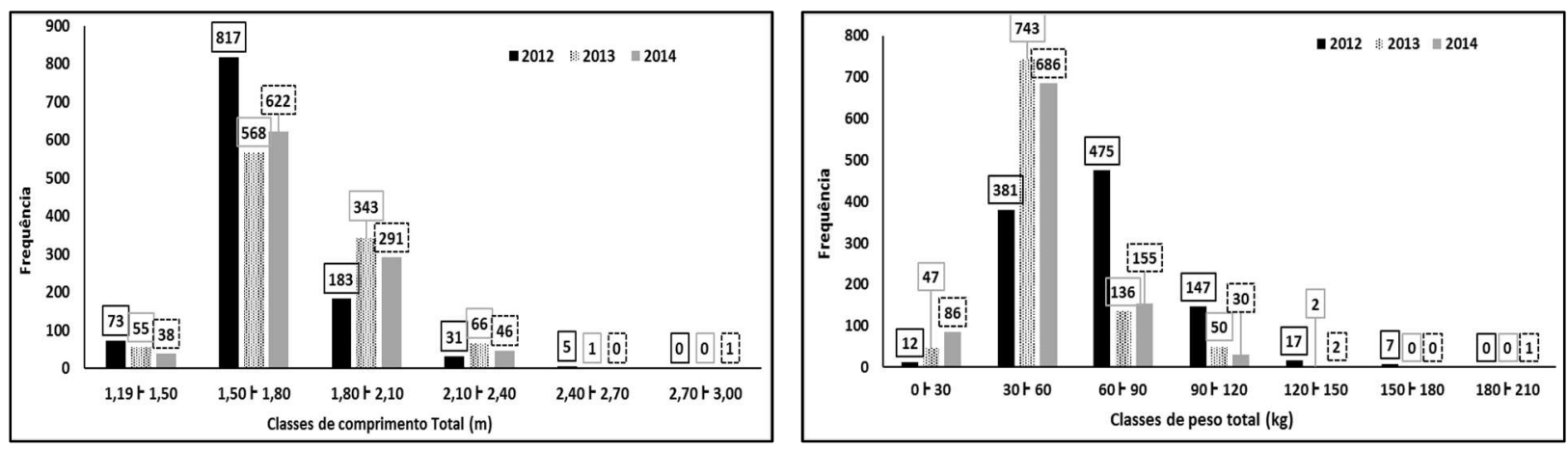

Figura 1: Distribuição por intervalo de classe de comprimento total $(\mathrm{m})$ e peso total $(\mathrm{kg})$ do pirarucu.

Os comunitários explotaram outras espécies de peixes ao longo da janela de captura, entretanto, os registros biométricos da pesca do tambaqui só foram iniciados de forma precária em 2013, quantificando 720 indivíduos (274 em 2013 e 446 em 2014), onde os exemplares capturados em 2013 totalizaram 1.882kg, com amplitude de peso total de $4 \mathrm{~kg}$ a $17 \mathrm{~kg}$ e uma média de $6,87( \pm 1,39) \mathrm{kg}$, e em 2014 , um peso total de $2.542 \mathrm{~kg}$, com amplitude de $4 \mathrm{~kg}$ a $13 \mathrm{~kg}$ e uma média de $5,18( \pm 1,37) \mathrm{kg}$. Além do tambaqui, foram explotados $390 \mathrm{~kg}$ de aruanã (Osteoglossum bicirrhosum), 119kg de surubim (Pseudoplatystoma spp.), 4.008kg de pirapitinga (Piaractus brachypomus) e 9.450kg de jaraqui (Semaprochilodus spp.) em 2014. O modelo matemático que melhor explicou a variação do peso total $(\mathrm{kg})$ em função do comprimento total $(\mathrm{m})$ para o pirarucu foi o potencial e o linear para o tambaqui (figura 2). 

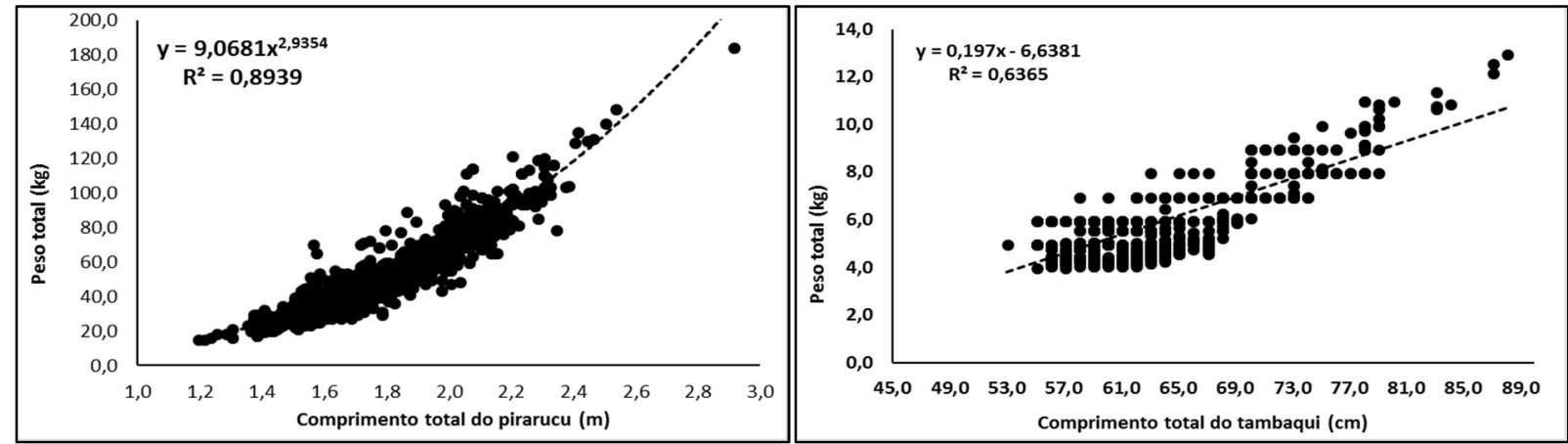

Figura 2: Modelos matemáticos da variação do peso total $(\mathrm{kg})$ em função do comprimento total $(\mathrm{m})$ do pirarucu e do tambaqui.

No contexto do aproveitamento das cotas de captura do pirarucu, nos anos de 2012, 2013 e 2014, foram contados 95.070 pirarucus, dos quais $43,06 \%$ foram adultos, resultando na possibilidade de pesca e comercialização de 9.861 pirarucus, entretanto, somente 30,16\% dos adultos liberados para a captura foram despescados (7,62\% da cota), evidenciando a perda da possibilidade de uso sustentável de 6.887 pirarucus e de aproximadamente 323 toneladas, se admitirmos um peso médio de 46,88 $\pm 17,35 \mathrm{~kg}$ (peso médio geral calculado para os 3 anos de manejo).

\section{Sexo e estádio de maturação gonadal do pirarucu.}

A identificação visual do sexo e estádio de maturação gonadal foi realizado em 2.965 exemplares adultos, não sendo realizada a determinação do sexo e estádio do tambaqui porque os exemplares capturados foram comercializados inteiros. Nos anos de 2012 e 2013, o percentual de pirarucus machos adultos capturados foi maior que o de fêmeas, invertendo no ano de 2014, como ilustra a figura 3, apesar do menor quantitativo despescados nesse ano.

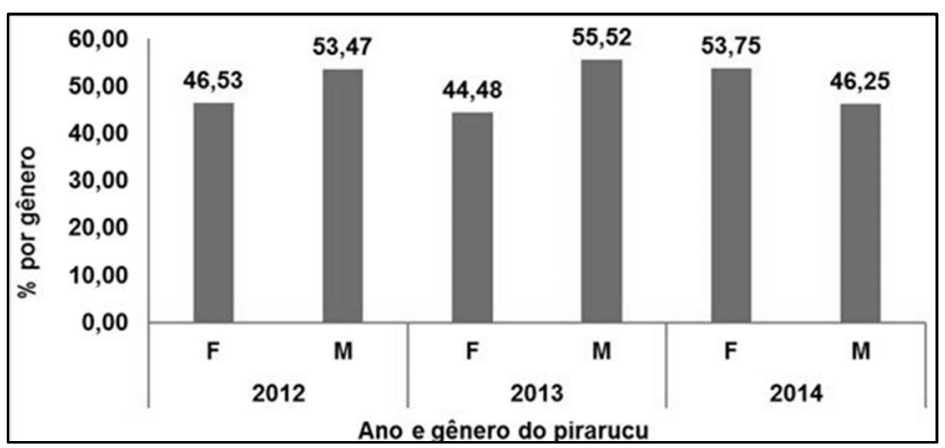

Figura 3: Percentual de machos e fêmeas de pirarucu capturados nos anos de 2012, 2013 e 2014.

A determinação do sexo e estádio gonadal realizada para o pirarucu permitiu identificar que $59,66 \%$ dos machos (M) e 57,29\% das fêmeas (F) estavam nos estádios III (maturação avançada), IV (maduro) e V (desovados) e que a maioria dos indivíduos (58,52\%) estavam prontos para reproduzir (III - 32,51\% e IV $21,92 \%$ ) ou desovaram (4,09\%). Além disso, não se observou exemplares $\geq 2,10 \mathrm{~m}$ nos dois primeiros estádios (I - imaturo e II - maturação inicial). No quadro 5 são apresentas as médias de comprimento total e peso total para os diferentes estádios gonadais dos exemplares de pirarucu, onde os indivíduos maiores e mais pesados tendem a estar nos estágios mais avançados. 
Quadro 4: Distribuição de frequência e percentual de pirarucus de acordo com a classe de comprimento total (m), gênero e estádio de maturação gonadal.

\begin{tabular}{|c|c|c|c|c|c|c|c|c|c|c|c|}
\hline \multirow{2}{*}{\multicolumn{2}{|c|}{$\begin{array}{c}\text { Estádio } \\
\text { Sexo }\end{array}$}} & \multicolumn{2}{|c|}{1} & \multicolumn{2}{|c|}{ II } & \multicolumn{2}{|c|}{ III } & \multicolumn{2}{|c|}{ IV } & \multicolumn{2}{|c|}{ V } \\
\hline & & $\mathrm{M}$ & $\mathrm{F}$ & $M$ & $\mathrm{~F}$ & $\mathrm{M}$ & $\mathrm{F}$ & $\mathrm{M}$ & $\mathrm{F}$ & $\mathrm{M}$ & $\mathrm{F}$ \\
\hline \multirow{5}{*}{ 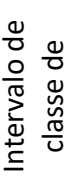 } & $1,50+1,80$ & 277 & 268 & 296 & 289 & 388 & 254 & 118 & 108 & & 6 \\
\hline & $1,80+2,10$ & 4 & 4 & 41 & 51 & 140 & 144 & 160 & 176 & 40 & 48 \\
\hline & $2,10 \vdash 2,40$ & & & & & 15 & 22 & 24 & 41 & 14 & 9 \\
\hline & $2,40+2,70$ & & & & & 1 & & 11 & 12 & 3 & \\
\hline & $2,70+3,00$ & & & & & & & & & & 1 \\
\hline \multicolumn{2}{|c|}{ Percentual } & 9,48 & 9,17 & 11,37 & 11,47 & 18,35 & 14,17 & 10,56 & 11,37 & 1,92 & 2,16 \\
\hline
\end{tabular}

Quadro 5: Gênero, comprimento total \pm (Desvio Padrão) e peso total \pm (Desvio Padrão) para os diferentes estádios gonadais dos exemplares de pirarucu amostrados.

\begin{tabular}{|c|c|c|c|c|}
\hline Estádio Gonadal & Sexo & Comprimento Total $(\mathrm{m})$ & Peso total médio (kg) & No \\
\hline \multirow{2}{*}{ I } & $\mathrm{F}$ & $1,57 \pm 0,07$ & $34,62 \pm 5,97$ & 272 \\
\cline { 2 - 5 } & $\mathrm{M}$ & $1,56 \pm 0,06$ & $33,20 \pm 4,72$ & 281 \\
\hline \multirow{2}{*}{$\mathrm{II}$} & $\mathrm{F}$ & $1,67 \pm 0,11$ & $41,81 \pm 8,93$ & 340 \\
\cline { 2 - 5 } & $\mathrm{M}$ & $1,66 \pm 0,11$ & $39,67 \pm 8,66$ & 337 \\
\hline \multirow{2}{*}{ III } & $\mathrm{F}$ & $1,78 \pm 0,15$ & $50,90 \pm 14,01$ & 420 \\
\cline { 2 - 5 } & $\mathrm{M}$ & $1,73 \pm 0,14$ & $46,69 \pm 13,40$ & 544 \\
\hline \multirow{2}{*}{$\mathrm{IV}$} & $\mathrm{F}$ & $1,91 \pm 0,18$ & $63,18 \pm 20,89$ & 337 \\
\cline { 2 - 6 } & $\mathrm{M}$ & $1,88 \pm 0,17$ & $60,30 \pm 18,22$ & 313 \\
\hline \multirow{2}{*}{$\mathrm{V}$} & $\mathrm{F}$ & $1,97 \pm 0,18$ & $66,73 \pm 21,46$ & 64 \\
\cline { 2 - 6 } & $\mathrm{M}$ & $1,99 \pm 0,14$ & $68,91 \pm 18,63$ & 57 \\
\hline
\end{tabular}

\section{Aspectos socioeconômicos}

De acordo com relatórios da gerência do UBPP II, a produção de pirarucu adultos de 2012 foi comercializada na forma de charuto ${ }^{4}$ de duas formas: 1 - Pelos próprios comunitários na feira da sede do município $(17$ pirarucus $=811 \mathrm{~kg}$ ) ao valor de $\mathrm{R} \$ 5,00 / \mathrm{kg} ; 2$ - Para duas empresas (1.034 pirarucus $=47.386 \mathrm{~kg})$, uma de Fonte Boa e outra de Santo Antônio do lça, ao custo de $R \$ 5,00 / \mathrm{kg}$ e $R \$ 5,50 / \mathrm{kg}$. A diferença no valor de comercialização resultou do local de aquisição do pescado, sendo o menor valor pago quando a entrega da produção foi feita para embarcações diretamente no porto das comunidades e o maior valor, quando a entrega foi realizada no porto de Santo Antônio do Iça. A comercialização resultou em um faturamento estimado de $\mathrm{R} \$ 237.707,50$, que dividido igualitariamente entre as 56 famílias (280 pessoas) de pescadores de 5 comunidades, viabilizou a cada pescador em torno de $R \$ 4.244,77$.

Em 2013 foram comercializados 33.323kg de pirarucu despescados em 5 comunidades, ao valor de $\mathrm{R} \$ 4,50 / \mathrm{kg}$, resultando um faturamento de $\mathrm{R} \$ 149.953,50$. Nesse ano, o pescado foi comercializado para uma única empresa de Manacapuru no valor de R\$450/kg. O processo de divisão do montante obtido foi realizado de acordo com o número de peixes explotados e o quantitativo de pescador de cada comunidade. Para a comunidade com maior quantitativo de pescadores (33), cada pescador recebeu aproximadamente $\mathrm{R} \$ 360,13$ e na comunidade com o menor quantitativo de pescadores (6), cada pescador recebeu $\mathrm{R} \$ 18.307,50$. A comercialização de tambaqui foi realizada em 2013, porém, não há registros do montante obtido e da forma de divisão.

Em 2014, foram comercializados $45.628 \mathrm{~kg}$ de pirarucu para cinco empresas (uma de Manacapuru, duas de Manaus e duas de Santo Antônio do lça) a $\mathrm{R} \$ 4,00 / \mathrm{kg}$, resultando um faturamento de $\mathrm{R} \$ 182.512,00$.

\footnotetext{
${ }^{4}$ Peixe inteiro eviscerado.
} 
Nesse ano, também foram comercializados $2.542 \mathrm{~kg}$ de tambaqui para uma empresa de Manacapuru e duas de Santo Antônio do Iça de $\mathrm{R} \$ 5,00$ a $R \$ 7,00 / \mathrm{kg}$ (de acordo com o porte), resultado um faturamento de $\mathrm{R} \$ 15.014,00$. De acordo com a gerência do UBPP II, durante esse período foram comercializadas no mercado do município um volume estimado de 14.269 toneladas de tambaqui, não declaradas a equipe técnica.

Foram comercializadas também de $33.952 \mathrm{~kg}$ de aruanã, surubim, pirapitinga e jaraqui para uma empresa de Manaus e uma de Manacapuru, ao valor de $\mathrm{R} \$ 1,50$ a $\mathrm{R} \$ 4,50 / \mathrm{kg}$ de acordo com a espécie, o que resultou em um faturamento de $R \$ 22.480,50$. O faturamento total em 2014 foi da ordem de $R \$ 220.006,50$, que divididos entre 85 famílias (763 pessoas) de pescadores, de acordo com a produção e número de pescadores de cada comunidade, resultou em uma amplitude de renda de $R \$ 372,48$ (para a comunidade com 33 pescadores) a $\mathrm{R} \$ 11.606,20$ (comunidade com 10 pescadores).

\section{DISCUSSÃO}

A sub-região do Alto Solimões (AM) onde se localiza Santo Antônio do Içá tem, na pesca, uma importante fonte de alimento para as populações locais e detém posição de destaque em termos de geração de emprego e renda como resultado de explotação de recursos pesqueiros para um mercado com uma cadeia produtiva consolidada (BRASIL, 2005; CAMARGO et al., 2010; FARIA-JUNIOR, 2013).

Porém, se a proximidade da região de tríplice fronteira entre Brasil, Colômbia e Peru, onde se localizam inúmeros frigoríficos e diversificados pontos de comercialização de pescado, vem favorecendo historicamente a produção e comercialização, também tem estimulado a saída de parte da produção de forma ilegal, trazendo perdas de benefícios para os pescadores e receita para a união, demandando iniciativas governamentais, como a implantação dos Polos de Produção de Pescado em Santo Antônio do Iça e Tabatinga, para fornecer gelo para os pescadores, recepcionar, armazenar e beneficiar o pescado para agregar valor e disponibilizar legalmente no mercado nacional e internacional (HONDA et al., 1975; MORAES et al., 2010; IBAMA, 2012; NAKAÚTH et al., 2012; MORAES, 2012; FARIA-JUNIOR, 2013).

A contratação do gerente para a UBPP II administrada pela Secretaria Executiva de Pesca e Aquicultura - SEPA/SEPROR possibilitou identificar os problemas relacionados a explotação de peixes no município de Santo Antônio do Içá e promover ações direcionadas ao uso sustentável do recurso e a distribuição de renda para os pescadores locais.

O esforço institucional para o manejo do pirarucu, seguindo a metodologia desenvolvida na Reserva de Desenvolvimento Sustentável de Mamirauá - RDS Mamirauá, resultou no georreferenciamento dos ambientes aquáticos com potencial para o manejo ao longo da calha do Rio Içá, a listagem de comunidades localizadas nas proximidades desses ambientes, quantificação dos pescadores e famílias residentes, realização de reuniões comunitárias e assembleias motivacionais e deliberativas para acordar as ações e definir o número de pescadores envolvidos para cada comunidade ou setor (área que abrange duas ou mais comunidades e os ambientes a serem inseridos no manejo).

Além disso, buscou-se definir as estratégias de monitoramento dos ambientes, a divisão dos trabalhos relacionados a vigilância ou fiscalização das áreas, além da escolha dos pescadores para 
participarem do curso de capacitação e certificação dos contadores de pirarucu para trabalharem no monitoramento, contagem e despesca do pirarucu (CASTELLO, 2004; VIANA et al., 2007; ARANTES et al., 2013; SILVA et al., 2013; CASARA, 2015). Entretanto, apesar das 25 comunidades e 142 lagos georreferenciados, somente 5 comunidades participaram das despescas em 2012 e 2013, passando para 8 (de 10 selecionadas) em 2014, com números de lagos despescados equivalentes ao número de comunidades.

Entre os motivadores desse baixo aproveitamento, segundo os relatórios técnicos da gerência do UBPP II, foram: No primeiro ano participaram comunidades da área do Projeto de Assentamento Florestal PAF/Rio Iça (parceria firmada com a SEPA/SEPROR) que serviram de base para mostrar o potencial existente do Rio Iça; e o comportamento atípico no pulso de inundação do Rio lça ocorrido nos anos de 2013 e 2014, que apesentou subida repentina ao longo do período de descida no nível das águas esperado para o verão, justamente na janela de captura permitida pelo IBAMA (anualmente de 01 de outubro a 29 de novembro).

Esse fator ambiental obrigou a suspensão das capturas na maioria das comunidades para não afugentar o pirarucu dos lagos, uma vez que, a estratégia utilizada para realizar as capturas é a espera do período de águas baixas, quando os canais que se ligam aos lagos secam, isolados esses ambientes, impedindo que os peixes se afugentem para outras áreas, facilitando as capturas (IDSM, 2011). Essa influência ambiental pode ser constatada na figura 4, bem como no estudo de Csasznik et al. (2015), onde demonstram que apesar do regime hidrológico do rio Putumayo-Içá ${ }^{5}$ possuir dois períodos hidrológicos definidos ao longo do ano e ascensões e recessões assimétricas, com cheia, entre abril e maio, e estiagem, entre setembro e outubro, é caracterizado como multimodal. O que deve ser levado em conta nas próximas ações de manejo.

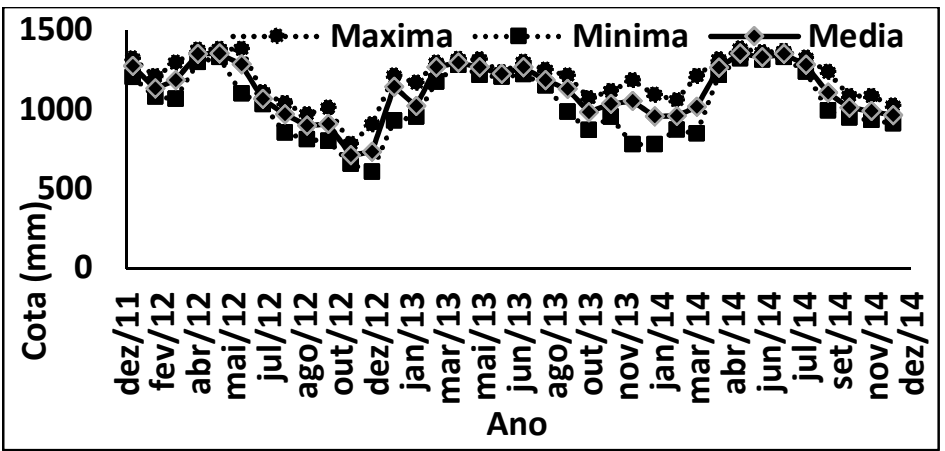

Figura 4: Flutuação do nível das águas do Rio Putumayo/lçá (Estação no 11444900 - comunidade Ipiranga Novo) nos anos de 2012, 2013 e 2014. Elaborado com base nos dados Agência Nacional das Águas.

Ainda em relação aos motivadores, tem-se a falta de apetrechos de pesca específicos em algumas comunidades demandou o compartilhamento dos petrechos entre comunidades em 2013, que só ocorria após o término das capturas em uma delas, fator que reduziu o tempo de pesca para algumas comunidades, que perderam a possibilidade de despesca devido ao término do período de captura permitido pelo IBAMA. Essa realidade é comum em outras áreas de manejo (IDSM, 2011), porém, poderia ser mitigada ou eliminada

\footnotetext{
${ }^{5}$ Rio Putumayo-Içá - afluentes da margem esquerda do rio Solimões que nasce nos contrafortes andinos do Equador, possui desembocadura de 700m de largura e deságua próximo à cidade de Santo Antônio do Içá. No total, possui 1645km de extensão, sendo 310km no estado do Amazonas (CSASZNIK et al., 2015).
} 
se um fundo composto por um percentual do faturamento obtido com a comercialização do pirarucu fosse destinado a compra de aparelhos de pesca, bem como de outras ações ligadas ao manejo.

Os interesses pessoais de familiares de comunitários envolvidos nas atividades de manejo em 2014 comprometeram a organização dos grupos de pescadores que realizariam as capturas, causando divergências e consequentemente, reduzindo o aproveitamento da cota liberada. No contexto da interferência externa, fica evidente a necessidade de maior discussão e fortalecimento da gerência compartilhada entre as instituições participantes e demais atores envolvidos para a resolução de conflitos de interesses, também observados em outras áreas onde o manejo do pirarucu foi implantado (AMARAL, 2009; BESSA et al., 2010; IDSM, 2011; WWF Brasil, 2015).

As análises dos dados de monitoramento coletados pela equipe técnica permitiram demonstrar o aumento no quantitativo e densidade de pirarucus em todos os ambientes utilizados e não utilizados nas despescas, o aumento do comprimento médio total e peso médio total dos indivíduos capturados, o maior quantitativo de exemplares de pirarucu com intervalo de peso entre $30 \vdash 60 \mathrm{~kg}$, a redução do número de bodecos abatidos a cada ano, o maior número de pescadores interessados em participar do manejo, a explotação de outras espécies de peixes, com destaque para o tambaqui, ao longo do período de captura do pirarucu e a distribuição de renda entre os pescadores e familiares envolvidos nas atividades de manejo.

Esses resultados corroboram com os obtidos em ouras áreas de manejo do pirarucu e se constituem indicadores de referência do êxito nas ações de manejo no município de Santo Antônio do Iça (VIANA et al., 2004; ARANTES et al., 2006; ARANTES et al., 2007; IDSM, 2011). Além disso, o processo de coleta de dados permitiu estabelecer a relação peso-comprimento do pirarucu e tambaqui, que em biologia pesqueira e ecologia de peixes são importantes instrumentos para avaliar o diferencial de crescimento entre e interespécies no ambiente natural (GOMIERO et al., 2003; TAVARES-DIAS et al., 2006, 2008).

No contexto reprodutivo, a determinação da distribuição por intervalo de comprimento e as médias de comprimento total e peso total do pirarucu para os diferentes estádios gonadais, mostraram que os indivíduos maiores e mais pesados tendem a estar nos estágios mais avançados no período em que a pesca é realizada. Além disso, o fato da maioria dos pirarucus amostrados estarem nas três últimas fases dos estádios gonadal e, portanto, próximos a iniciarem o período reprodutivo ou já ter reproduzido no final da estação seca corrobora com os estudos de Castello (2008a, 2008b) e Lopes et al. (2009).

O que está diretamente relacionado como a estratégia que essa espécie desenvolve em ambientes de lagos, formando casais na estação seca e quando o nível do rio sobe, passando a construir um ninho na beira das florestas de restinga que circundam os ambientes de lagos, ressacas e paranás, onde depositam, fertilizam e cuida dos ovos até que eclodam, com indícios que o gênero possa fazer múltiplas desovas em um mesmo ano (CASTELLO, 2008a, 2008b; NEVES, 1995), resultados que, além de permitirem o entendimento do momento em que os peixes estão prontos para reproduzir, fornecendo informações importantes para a conservação da espécie, demostrando que a estratégia de limitar as capturas para em torno de $30 \%$ dos indivíduos contados (VIANA et al., 2004; CASTELLO, 2004) permitindo que os demais possam reproduzir, é exitosa. 
Para o tambaqui, o registro do aumento na quantidade de exemplares capturados e do peso total em 2014 poderia indicar o sucesso na estratégia de manejo, porém, a redução no peso médio calculada alerta para a necessidade de maior atenção ao monitoramento da pesca dessa espécie, no sentido de evitar a sobrepesca, assim como para as demais espécies utilizadas, de forma a quantificar o benefício do manejo para o recurso explotado.

Na ótica socioeconômica, o trabalho de monitoramento e contagem vinculados ao manejo do pirarucu realizado pelas comunidades em conjunto com a equipe técnica da SEPA entre os meses de março a agosto, subsidiam relatórios técnicos e as solicitações das cotas de captura ao IBAMA, a partir da qual se realizam contatos com os compradores para o estabelecimento dos valores de venda e a quantidade demanda para cada comunidade ou setor (VIANA et al., 2004; ARANTES et al., 2007; IDSM, 2011).

A captura do tambaqui, espécie de elevado valor comercial e preferência popular não só no Estado do Amazonas, mas em toda a região Norte (GANDRA, 2010), foi realizada durante o mês de setembro, o montante capturado foi declarado ao IBAMA e não foram comercializados indivíduos abaixo do tamanho mínimo de captura $(55 \mathrm{~cm})$. A partir do mês de outubro os pescadores se dedicam a pesca do pirarucu, ocorrendo a captura de outras espécies em conjunto.

A comercialização da produção foi realizada pela Associação das Comunidades Manejadoras do Rio Içá - Asscomal/Rio Içá e representantes das comunidades de cada setor, sendo limitada a participação da SEPA ao conhecimento do montante obtido, para não interferir na autonomia das lideranças comunitárias e Asscomal, como nos procedimentos descritos por Amaral (2007) para o pirarucu manejado nas reservas Mamirauá e Amanã. O faturamento obtido, como regra, deve ser dividido igualitariamente entre as famílias dos pescadores, de acordo com a participação efetiva nas atividades relacionadas ao manejo e a cota de captura de cada comunidade.

Essa divisão, de acordo com os procedimentos desenvolvidos pelo IDSM (2011), deve ser realizada de acordo com um Regimento Interno, havendo a necessidade de prestação de contas de seus gastos por meio de notas fiscais e recibos devidamente preenchidos, todavia, as próprias lideranças optaram por definir os procedimentos em Assembleias com registro em ata. Esse processo de repartição dos benefícios do manejo necessita de ajustes, uma vez que, segundo os relatórios técnicos, ocorreram variação no montante recebido em algumas famílias, de acordo com a cota previamente estipulada, gerando descontentamentos.

Apesar dos fatores ambientais que limitaram o melhor aproveitamento das cotas de captura e da ocorrência de divergências quanto a divisão e repasse dos ganhos econômicos com o manejo, os três anos de manejo resultaram em um faturamento total estimado em $\mathrm{R} \$ 607.667,50$, beneficiando até 85 pescadores e familiares (763 pessoas), colaborando para a conservação do pirarucu e demais espécies que ocorrem nas áreas manejadas, distribuindo renda para o pescador que tem uma alternativa para realizar a pesca de forma legal e disseminando os benefícios do uso sustentável dos recursos pesqueiros (QUEIROZ et al., 1999; AMARAL, 2007; ARANTES et al., 2007; VIANA et al., 2007; CASTELLO et al., 2011; IDSM, 2011; BESSA et al., 2010; ROSA, 2014; CSASZNIK et al., 2015). 
É importante inferir que esse modelo de manejo pesqueiro do pirarucu só obteve eficiência em Santo Antônio do Içá e demais municípios no Estado do Amazonas em decorrência da edição de uma Instrução Normativa - IN complementar a IN no 34 (18/06/2004) que proibia anualmente a captura, a comercialização e o transporte do pirarucu nos Estados do Amazonas, Pará, Acre e Amapá, no período de 1o de dezembro a 31 de maio (art. 2ㅇ), permitindo a exploração do pirarucu no resto do ano com medidas de tamanho mínimo de 1,5m de comprimento total - CT para o peixe inteiro, 1,2m de CT para a manta fresca e de 1,1m de CT para a manta seca (art. 4ㅇ).

Essa IN complementar, denominada de IN № 1 (01/06/2005), no seu art. 1ㅇp proibiu anualmente a pesca, o transporte, a armazenagem e a comercialização do pirarucu no estado do Amazonas, durante o período de $1^{\circ}$ de junho de a 30 de novembro. No art. 2ํㅡ, excluiu da proibição os produtos oriundos de piscicultura devidamente registrada, e acompanhados de comprovante de origem, bem como a pesca de caráter científico e pesca proveniente dos manejos de lagos autorizados pela GEREX/AM e no art. 3o autorizou a pesca em áreas de manejo situadas em unidades de conservação de uso direto ou inseridas em Acordos de Pesca baseados na Instrução Normativa IBAMA no 29, de 31 de dezembro 2002.

Dessa forma, a proibição da pesca do pirarucu durante todo o ano, ressaltadas as realizadas em áreas de manejo, é pré-requisito para o uso sustentável do recurso e a recuperação das populações naturais, uma vez que, onde não há uma legislação complementar para impedir a captura do pirarucu ao longo de todo o ano, não existe área de manejo ou Acordo de Pesca oficialmente delimitada e onde não há uma fiscalização eficiente, as populações de pirarucu estão em declínio (CASTELLO et al., 2010; ARANTES et al., 2013).

\section{CONCLUSÕES}

O manejo pesqueiro em Santo Antônio do Içá apresenta indicativos de sucesso nas estratégias utilizadas com base no modelo desenvolvido em Mamirauá. Proporcionou o incremento populacional, o aumento das medidas biométricas e a redução do abate de juvenis (bodecos) do pirarucu em todas as áreas monitoradas, viabilizou a utilização de outras espécies como o tambaqui, a aruanã, o surubim, a pirapitinga e o jaraqui, proporcionou a geração e distribuição de renda entre os atores envolvidos e a perspectivas de ampliação da capacidade de captura e comercialização, mediante o potencial projetado a partir do georreferenciamento dos ambientes aquáticos distribuídos ao longo da calha do Rio Iça.

Apesar desses resultados, foi observada a necessidade de maior atenção ao monitoramento das espécies explotadas, o fortalecimento das lideranças locais e maior proximidade institucional para otimizar o planejamento das futuras ações de manejo, realizar o aproveitamento mais efetivo do potencial pesqueiro e ampliar os benefícios do manejo para os pescadores e seus familiares, além de mitigar conflitos internos.

\section{REFERÊNCIAS}

ALMEIDA, O. T.; MCGRATH, D. G.; RUFFINO, M. L.. The commercial fisheries of the lower Amazon: an economic analysis. Fisheries Management and Ecology, v.8, p.253-269, 2001. DOI: http://doi.org/10.1046/i.1365$\underline{2400.2001 .00234 . x}$
AMARAL, E. S. R.. A comunidade e o mercado: os desafios na comercialização de pirarucu manejado das reservas Mamirauá e Amanã, Amazonas, Brasil. UAKARI, v.3, n.2, p.717, 2007. 
AMARAL, E. S. R.. O manejo comunitário de pirarucu (Arapaima gigas) como alternativa econômica para os pescadores das Reservas Amanã e Mamirauá, Amazonas, Brasil. Dissertação (Mestrado em Gestão de Recursos Naturais e Desenvolvimento Local na Amazônia) Universidade Federal do Pará, Belém, 2009.

ARANTES, C. C.; CASTELLO, L.; GARCEZ, D. S.. Variações entre contagens de Arapaima gigas (Schinz) (Osteoglossomorpha, Osteoglossidae) feitas por pescadores individualmente em Mamirauá, Brasil. Pan-American Journal of Aquatic Sciences, v.2, n.3, p.263-269, 2007.

ARANTES, C. C.; GARCEZ, D. G.; CASTELLO, L.. Densidades de pirarucu (Arapaima gigas, Teleostei, Osteoglossidae) nas Reservas de Desenvolvimento Sustentável Mamirauá e Amanã, Amazonas, Brasil. UAKARI, Belém, n.2, p.37-43, 2006.

ARANTES, C.; CASTELLO, L.. Implicações da biologia, ecologia e contagens para o manejo do pirarucu. In: AMARAL, E.. Biologia, conservação e manejo participativo de pirarucus na Pan-Amazônia. Tefé: IDSM, 2013.

BARTHEM, R. B.; PETRERE, J. R.; ISAAC, V.; RIBEIRO, M. C. L.; MCGRATH, D.; VIEIRA, I. J. A.; BARCO, M. V.. A pesca na Amazônia: problemas e perspectivas para o seu manejo. In: SEMINÁRIO SOBRE 'MANEJO DA VIDA SILVESTRE'. Anais. Belém: CCC, 1992.

BATISTA, V. S.; INHAMUNS, A.; FREITAS, C. E.; FREIRE-BRASIL, D.. Characterization of the fishery in river communities in the low-Solimões/high-Amazon region. Fisheries Management and Ecology, v.5, p.419-435, 1998. DOI: http://doi.org/10.1046/j.1365-2400.1998.550419.x

BESSA, J. D. O.; LIMA, A. C.. Manejo de Pesca do Pirarucu (Arapaima gigas) no Estado do Amazonas: Erros, Acertos e Perspectivas Futuras. In: SEMINÁRIO INTERNACIONAL DE CIÊNCIAS DO AMBIENTE E SUSTENTABILIDADE NA AMAZÔNIA. Anais. Manaus: UFAM, 2010. BRASIL. Boletim Estatístico da Pesca e Aquicultura. Brasília: MPA, 2012.

BRASIL. Programa de Desenvolvimento da Faixa de Fronteira. Brasília: MIN, 2005.

BRELAZ, R. L.; FARIA-JUNIOR, C. H.; RIBEIRO, F. R. V.. Caracterização da atividade pesqueira na comunidade Vila Flexal do município de Óbidos, Pará, Brasil: subsídios para gestão dos recursos. Scientia Amazonia, v.7, n.1, p.134-155, 2018.

CAMARGO, S. A. F.; CAMARGO, T. R. L.. O manejo da pesca do pirarucu Arapaima gigas na fronteira Peru, Brasil e Colômbia. In: ENCONTRO NACIONAL DO CONPEDI, 19. Anais. Fortaleza: CONPEDI, 2010.

CARDOSO, R. S.; BATISTA, V. S.; FARIA-JÚNIOR, C. H.; MARTINS, W. R.. Aspectos econômicos e operacionais das viagens da frota pesqueira de Manaus, Amazônia Central. Acta Amazônica, v.34, n.2, p.301-307, 2004. DOI: http://doi.org/10.1590/S0044-59672004000200016

CARDOSO, R. S.; FARIA-JUNIOR, C. H.. Análise econômica das pescarias em canoas motorizadas no município de Parintins, região do Baixo rio Amazonas, Brasil. Scientia Amazonia, v.6, n.3, p.58-68, 2017.
CASARA, H. N.. Avaliação da produção e do impacto econômico do aumento do tamanho de captura no manejo de pirarucus (Arapaima spp.) em sete áreas protegidas na Amazônia Central Brasileira. Dissertação (Mestrado em Gestão de Áreas Protegidas na Amazônia) - Instituto Nacional de Pesquisas da Amazônia, Manaus, 2015.

CASTELLO, L., STEWART, D. J., ARANTES, C. C.. Modeling population dynamics and conservation of arapaima in the Amazon. Reviews in Fish Biology and Fisheries, v.21, n.3, p.623-640, 2011a. DOI: http://doi.org/10.1007/s11160-0119241-7

CASTELLO, L.. A method to count pirarucu fishers, assessment and management. American Journal of Fisheries Management, v.24, p.379-389, 2004. DOI:

https://doi.org/10.1577/M02-024.1

CASTELLO, L.. Lateral migration of Arapaima gigas in floodplains of the Amazon. Ecology of Freshwater Fish, v.17, p.38-46, 2008a. DOI: http://doi.org/10.1111/i.16000633.2007.00255.x

CASTELLO, L.. Nests of pirarucu Arapaima gigas in floodplains of the Amazon: habitat and relation to spawner abundance. Journal of Fish Biology, v.72, p.1-9, 2008b. DOI: https://doi.org/10.1111/j.1095-8649.2007.01778.x

CASTELLO, L.; STEWART, D. J.. Assessing CITES non-detriment finding procedures for Arapaima in Brazil. Journal of Applied Ichthyology, v.26, p.49-56, 2010. DOI:

https://doi.org/10.1111/j.1439-0426.2009.01355.x

CASTELLO, L.; STEWART, D. J.; ARANTES, C. C.. O que sabemos e precisamos fazer a respeito da conservação do pirarucu (Arapaima spp.) na Amazônia. Biologia, conservação e manejo participativo de pirarucus na PanAmazônia. Tefé: IDSM, 2013.

CERDEIRA, R. G. P.; RUFFINO, M. L.; ISAAC, V. J.. Consumo de pescado e outros alimentos nas comunidades ribeirinhas do Lago Grande de Monte Alegre. Acta Amazônica, v.27, n.3, p.213-227, 1997.

COELHO, A. C. S.; FARIA-JUNIOR, C. H.; SOUSA, K. N. S.. Fatores que influenciam a compra de peixes por classe social no município de Santarém-PA. Agroecossistemas, v.9, n.1, p.62-83, 2017. DOI:

http://doi.org/10.18542/ragros.v9i1.4773

CRAMPTON, W. G. R.. Os peixes da Reserva Mamirauá: diversidade e história natural na planície alagável da Amazônia. In: QUEIROZ, H. L.; CRAMPTON, W.. Estratégias para o manejo de recursos pesqueiros em Mamirauá. Brasília: MCT, 1999.

CSASZNIK, M.; CONCHY, T. S. X.; SILVA, J. S. CALMANT, S.; SEYLER, F.. Caracterização do regime hidrológico da Bacia do rio Putumayo-Içá através da altimetria espacial. In: SIMPÓSIO BRASILEIRO DE RECURSOS HÍDRICOS, SEGURANÇA HÍDRICA E DESENVOLVIMENTO SUSTENTÁVEL: DESAFIOS DO CONHECIMENTO E DA GESTÃO, 21. Anais. Brasília: CCUG, 2015.

FARIA-JUNIOR, C. H.. Avaliação da rentabilidade da pesca comercial artesanal e primeira comercialização do pescado no estado do Amazonas, Brasil. Tese (Doutorado em 
Ciências Pesqueiras nos Trópicos) - Universidade Federal do Amazonas, Manaus, 2013.

FARIA-JÚNIOR, C. H.; BATISTA, V. S.. Repartição da renda derivada da primeira comercialização do pescado na pesca comercial artesanal que abastece Manaus (Estado do Amazonas, Brasil) Acta Scientarum: Human and Social Sciences, Maringá, v.28, n.1, p.131-136, 2006. DOI: http://doi.org/10.4025/actascihumansoc.v28i1.190

GANDRA, A. L.. O mercado de pescado da região metropolitana de Manaus. Manaus: CFC, 2010.

GOMIERO, L. M.; BRAGA, F. M. S.. Relação peso comprimento e fator de condição para Cichla cf. ocellaris e Cichla monoculus (Perciformes, Cichlidae) no reservatório de Volta Grande, rio Grande-MG/SP. Acta Scientiarum, v.25, p.79-86, 2003. DOI:

http://doi.org/10.4025/actascibiolsci.v25i1.2119

HILBORN, R.; WALTERS, C. J.. Quantitative fisheries stock assessment: choice, dynamics, and uncertainty. New York: Chapman and Hall, 1992. DOI:

https://doi.org/10.1086/417864

HONDA, E. M. S.; CORREA, C. M.; CASTELO, F. P.; ZAPELINI, E. A.. Aspectos gerais do pescado no Amazonas. Acta Amazônica, v.5, n.1, p.87-94, 1975. DOI: http://doi.org/10.1590/1809-43921975051087

IBAMA. Instituto Brasileiro do Meio Ambiente e dos Recursos Naturais Renováveis. 0 setor pesqueiro na Amazônia: análise da situação atual e tendências do desenvolvimento a indústria da pesca. Manaus: IBAMA, 2007.

IBAMA. Instituto Brasileiro do Meio Ambiente e dos Recursos Naturais Renováveis. Peixes e pesca no Solimões-Amazonas: uma avaliação integrada. Brasília: IBAMA, 2012. DOI: http://doi.org/10.4025/actascibiolsci.v20i0.4470

IDSM. Instituto de Desenvolvimento Sustentável Mamirauá. Manejo do Pirarucu (Arapaima gigas) em lagos de várzea de uso exclusivo de pescadores urbanos: baseado na experiência do Instituto Mamirauá junto a Colônia de Pescadores Z-23 de Maraã na cogestão do complexo do Lago Preto, Reserva de Desenvolvimento Sustentável Mamirauá RDSM. Tefé: IDSM, 2011.

IPT. Instituto de Pesquisas Tecnológicas. Avaliação da atual frota pesqueira amazonense e proposição de novas concepções. São Paulo: IPT, 1979.

ISAAC, V. J.; ROCHA, V. L. C.; MOTA, S.. Considerações sobre a legislação da 'piracema' e outras restrições da pesca da região do Médio Amazonas. In: FURTADO, L. G.; LEITÃO, W.; MELO, A. F.. Povos das águas: realidade e perspectivas na Amazônia. Belém: MPEG, 1993. p.188-211.

LOPES, K.; QUEIROZ, H. L.. Uma revisão das fases de desenvolvimento gonadal de pirarucus Arapaima gigas (SCHINZ, 1822). UAKARI, v.5, n.1, p.39-48, 2009.

MCGRATH, D. G.; CASTRO, F.; FUTEMMA, C.; AMARAL, B. D.; CALABRIA, J.. Fisheries and evolution of resource management on the Lower Amazon floodplain. Human Ecology, v.21, p.167-195, 1993. DOI:

https://doi.org/10.1007/BF00889358
MORAES, A. O.. Peixes, redes e cidades: aspectos socioambientais da pesca comercial de bagres no Médio e Alto Solimões - AM. Dissertação (Mestrado em Ciências do Ambiente e Sustentabilidade na Amazônia) - Universidade Federal do Amazonas, Manaus, 2012.

MORAES, A. O.; SCHOR, T.; ALVES-GOMES, J. A.. Relações de trabalho e transporte na pesca de bagres no rio Solimões AM. Novos Cadernos NAEA, v.13, n.1, p.155-170, 2010. DOI: http://doi.org/10.5801/ncn.v13i1.450

NAKAÚTH, A. C. S. S.; NAKAUTH, R. F.. Programa 'Produzindo Peixe no Alto Solimões: desafios ao desenvolvimento da pesca e piscicultura'. In: ENCONTRO NACIONAL DOS NÚCLEOS DE PESQUISA APLICADA EM PESCA E AQUICULTURA, 4. Anais. Foz do Iguaçu: IFECTF, 2012.

NEVES, A. M. B.. Conhecimento atual sobre o pirarucu, Arapaima gigas (CUVIER, 1817). Boletim do Museu Paraense Emílio Goeldi, v.11, p.33-56, 1995.

PARENTE, V. M.. A economia da pesca em Manaus: organização da produção e da comercialização. Dissertação (Mestrado em Economia) - Universidade Federal do Rio de Janeiro, Rio de Janeiro, 1996.

PETRERE, M.. As comunidades humanas ribeirinhas da Amazônia e suas transformações sociais. In: ENCONTRO DE CIÊNCIAS SOCIAIS E O MAR NO BRASIL, 4. Anais. São Paulo: 1992. DOI: http://doi.org/10.20435/1518-70122016107

PETRERE, M.. Ecology of the fisheries in the River Amazon and tributaries in the Amazonas state (Brazil). Tese (PósDoutorado) - University of East Anglia, Norwich, 1982.

PETRERE, M.. Pesca e esforço de pesca no estado do Amazonas. Esforço e captura por unidade de esforço. Acta Amazônica, v.8, n.3, p.439-454, 1978b. DOI: http://doi.org/10.1590/1809-43921978083439

PETRERE, M.. Pesca e esforço de pesca no estado do Amazonas. Locais e aparelhos de captura e estatística de desembarque. Acta Amazônica, v.8, n.2, p.1-54, 1978a. Dol: http://doi.org/10.1590/1809-439219780832s005

QUEIROZ, H. L.; SARDINHA, A. D. A.. Preservação e o uso sustentado dos pirarucus (Arapaima gigas, Osteoglossidae) em Mamirauá. In: QUEIROZ, H. L.; CRAMPTON, W. G. R.. Estratégias para manejo de recursos pesqueiros em Mamirauá. Tefé: SCM, 1999.

ROSA, F.. Pescadores avaliam o manejo do pirarucu na Reserva Mamirauá. O Macaqueiro, v.14, n.63, 2014.

RUFFINO, M. L.; ISAAC, V. J.. Ciclo reprodutivo de algumas espécies de peixes comerciais do Baixo Amazonas. Brasília: IBAMA, 2000.

SILVA, R. B.; GONÇALVES. A. C. T; MARINHO, J. C.. Contagem e Censo Populacional de Pirarucu. Tefé: IDSM, 2013.

TAVARES-DIAS, M.; MARCON, J. L.; LEMOS, J. R. G.; FIM, J. D. I.; AFFONSO, E. G.; ONO, E. A.. Índices de condição corporal em juvenis de Brycon amazonicus (SPIX \& AGASSIZ, 1829) e Colossoma macropomum (CUVIER, 1818) na Amazônia. Boletim do Instituto de Pesca, v.34, p.197-204, 2008. 
TAVARES-DIAS, M.; MORAES, F. R.; MARTINS, M. L.. Equação da relação peso-comprimento, fator de condição, relação hepato e esplenosomática de 11 teleósteos dulciaqüícolas cultivados no Brasil. In: CONGRESO IBEROAMERICANO VIRTUAL DE ACUICULTURA, 4. Anais. Saragoça: 2006.

VAZZOLER, A. E. A.. Biologia da reprodução de peixes teleósteos: teoria e prática. Maringá: EDUEM, 1996.

VIANA, J. P.; CASTELLO, L.; DAMASCENO, J. M. B.; AMARAL, E. S. R.; ESTUPIÑÁN, G. M. B.; ARANTES, C.; BATISTA, G. S.; GARCEZ, D. S.; BARBOS, S.. Manejo Comunitário do Pirarucu Arapaima gigas na Reserva de Desenvolvimento Sustentável Mamirauá - Amazonas, Brasil. In: Áreas Aquáticas Protegidas como Instrumento de Gestão Pesqueira. Brasília: MMA, 2007.
VIANA, J. P.; DAMASCENO, J. M. B.; CRAPTON, W. G. R. Economic Incentives for Sustainable Community Management of fishery Resources in the Mamirauá Sustentainable Development Reserve, Amazonas, Brasil. In: SILVIUS, K. M.; BODMER, R.; FRAGOSO, J. M. V.. People in Nature: wildlife conservation in South and Central América. New York: Columbia University Press, 2004. p.139-154.

WWF Brasil. World Wide Fund for Nature. Plano de Melhoria para a Certificação da Pescaria do Pirarucu em Feijó. Brasília: WWF Brasil, 2015.

ZAR, J. H.. Biostatystical Analisys. New York: Prentice-Hall, 1999.

A CBPC - Companhia Brasileira de Produção Científica (CNPJ: 11.221.422/0001-03) detém os direitos materiais desta publicação. Os direitos referem-se à publicação do trabalho em qualquer parte do mundo, incluindo os direitos às renovações, expansões e disseminações da contribuição, bem como outros direitos subsidiários. Todos os trabalhos publicados eletronicamente poderão posteriormente ser publicados em coletâneas impressas sob coordenação da Sustenere Publishing, da Companhia Brasileira de Produção Científica e seus parceiros autorizados. Os (as) autores (as) preservam os direitos autorais, mas não têm permissão para a publicação da contribuição em outro meio, impresso ou digital, em português ou em tradução. 